\title{
NGHIÊN CỨU ĐẶC ĐIỂM HÌNH ẢNH CỦA SIÊU ÂM VÀ CHỤP CẮT LỚP VI TÍNH 64 DÃY ĐẦ DÒ TRONG CHẨN ĐOÁN PHİNH ĐỘNG MẠCH CHỦ BỤNG
}

\author{
Phạm Quang Tuấn*, Nguyễn Tá Đông*, Trần Chí Thành*, Đoàn Đức Hoằng*
}

\section{TÓM TÁT}

Gồm 36 bệnh nhân được chẩn đoán phình động mạch chủ bụng (PĐMCB) trên siêu âm và cắt lớp vi tính tại Bệnh viện Trung Ương Huế. Bệnh lý gặp 83,3\% ở nam giới, chủ yếu > 60 tuổi. Yếu tố nguy cơ là hút thuốc lá và tăng huyết áp; 69,4\% bệnh nhân vào viện với triệu chứng đau bụng. Đa số khối phình có đường kính ngang $\leq$ $5 \mathrm{~cm}(50 \%$ trên siêu âm và $55,5 \%$ trên CLVT). Đường kính trước sau của khối phình phần lớn $\leq$ $5 \mathrm{~cm}(52,7 \%$ trên siêu âm và $58,4 \%$ trên CLVT). Chiều dài của khối phình từ $6-10 \mathrm{~cm}$ chiếm tỉ lệ cao nhất $(61,1 \%$ trên siêu âm và $58,3 \%$ trên CLVT). Khối PĐMCB có hình thoi chiếm 91,7\% trên cả siêu âm và CLVT. Vị trí thường nằm dưới chổ xuất phát của ĐM thận $(88,8 \%$ trên siêu âm và $91,7 \%$ trên CLVT). Và đa phần khối phình lan tới ĐM chậu $(83,3 \%$ trên siêu âm và $86,1 \%$ trên CLVT). PĐMCB thường kèm theo xơ vữa vôi hóa thành mạch $(75 \%$ trên siêu âm và $80,6 \%$ trên CLVT), đồng thời 5,6\% trường hợp có kèm theo bóc tách nội mạc. Tình trạng huyết khối bám thành chiếm tỉ lệ cao $(88,8 \%$ trên siêu âm và 91,7\% trên CLVT). Có sự phù hợp chặt chẽ giữa các thông số thu được trên siêu âm và CLVT trong bệnh lý PĐMCB với kappa $>0,7(\mathrm{P}<0,001)$.

\section{SUMMARY}

36 patients with abdominal aortic aneurysm were diagnotised by arterial doppler ECHO and 64 slide CT scaner from oct, 2012 to oct, 2013. Rate of the patients with abdominal aortic aneurysm was $83.3 \%$ in male and almost in elders above 60 years old. Risk factors were often smoking, hypertension; 69,4\% patients hospitalized ducing to abdominal pain. Almost of enlarged areas had inside diameter $\leq 5 \mathrm{~cm} \mathrm{(50 \%}$ by ECHO and $55.5 \%$ by 64 side CT scaner); Posterior - lateral diameter $\leq 5 \mathrm{~cm}(52.7 \%$ by ECHO and $58.4 \%$ by 64 side CT scaner); The enlarged areas (had length from $6-10 \mathrm{~cm}$ ) were highest rate $(61.1 \%$ by ECHO and $58.3 \%$ by 64 side CT scaner). Abdominal aortic aneurysms were often associated with arteroscleroses and calcifications ( $75 \%$ by ECHO and $80.6 \%$ by 64 side CT scaner) and $5.6 \%$ cases associated ocupture. Rate of enlarged areas having thrombus was very high ( $88.8 \%$ by ECHO and $91.7 \%$ by 64 side CT scaner). There was compatibility (with Kappa score > 70\%) between.

parametes of enlarged areas valued by ECHO and by 64 side CT scaner in the patients with abdominal aortic aneurysm $(\mathrm{p}<0.001)$.

\section{I. ĐặT VẤN ĐỀ}

Phình động mạch chủ bụng (PĐMCB) là bệnh lý hay gặp ở người lớn tuổi, tỉ lệ tử vong do vỡ PĐMCB đứng hàng thứ 10 trong các nguyên nhân gây tử vong hàng năm ở nam giới trên 55 tuổi. Vấn đề phát hiện bệnh sớm có vai trò hết sức quan trọng. Các phương tiện chẩn đoán hình ảnh cho phép chẩn đoán sớm, chính xác các dấu hiệu và giai đoạn của phình động mạch chủ bụng.

\footnotetext{
* Bệnh Viện TW Hué

Ngườ chịu trách nhiệm khoa học: Ths Đoàn Đức Hoằng Ngày nhận bài: 20/03/2015 - Ngày Cho Phép Đăng: 27/03/2015 Phản Biện Khoa học: PGS.TS. Đặng Ngọc Hùng PGS.TS. Lê Ngọc Thành
} 
Siêu âm là phương tiện chẩn đoán đơn giản, dễ thực hiện. Và gần đây, chụp cắt lớp vi tính (CLVT) không ngừng được cải tiến và hoàn thiện hơn, các thế hệ máy đa dãy đầu dò lại càng thể hiện rõ ưu việt hơn, khảo sát rất tốt các bộ phận chuyển động (tim, mạch máu) [10]. Chính vì vậy chúng tôi thực hiện đề tài nhằm hai mục tiêu:

1. Mô tả đặc điểm hình ảnh của PĐMCB trên siêu âm và chụp CLVT 64 dãy đầu dò.

2. Đối chiếu kết quả của siêu âm và CLVT trong chẩn đoán PĐMCB.

\section{II. ĐỐI TƯợG VÀ PHƯONG PHÁP NGHIÊN CÚU}

\section{1. Đối tượng nghiên cứu}

Là những bệnh nhân được chẩn đoán phình động mạch chủ bụng trên siêu âm và cắt lớp vi tính tại Bệnh viện Trung Ương Huế, trong thời gian từ tháng 3/2012 đến tháng 7/2013.

\section{2. phương pháp nghiên cứu}

Mô tả cắt ngang. Từ hồ sơ bệnh án đã được lựa chọn, tiến hành lập ra phiếu gồm các thông tin cụ thể như: Tuổi, giới, lý do vào viện, yếu tố nguy cơ. Sử dụng máy siêu âm Doppler màu hiệu Siemens Acuson (Đức), cấu hình gồm 2D, Doppler màu, Doppler xung và Doppler liên tục. Hình ảnh cắt lớp vi tính được thực hiện trên máy CLVT 64 dãy đầu dò hiệu Philips.

Phình động mạch chủ bụng khi đường kính lớn hơn $30 \mathrm{~mm}$ hoặc lớn hơn 1,5 lần so với đường kính động mạch chủ bình thường đoạn trên chỗ phình [11].

\section{KẾT QUẢ}

\subsection{Các đặc điểm lâm sàng và cận lâm sàng của đối tượng nghiên cứu:}

\subsection{1. Đặc điểm tuổi và giới}

Bảng 3.1. Tỷ lệ phình ĐMC bụng theo tuổi và giới

\begin{tabular}{|c|c|c|c|}
\hline \multicolumn{2}{|c|}{ Đặc điểm tuổi và giới } & N & \% \\
\hline \multirow{2}{*}{ Giới } & Nam & 30 & 83,3 \\
\cline { 2 - 4 } & Nữ & 6 & 16,7 \\
\hline \multirow{2}{*}{$\begin{array}{c}\text { Tuổi } \\
\text { (năm) }\end{array}$} & $\leq 50$ & 1 & 2,8 \\
\cline { 2 - 4 } & $51-60$ & 8 & 22,2 \\
\cline { 2 - 4 } & $61-70$ & 5 & 13,9 \\
\cline { 2 - 4 } & $71-80$ & 17 & 47,2 \\
\cline { 2 - 4 } & $>80$ & 5 & 13,9 \\
\hline
\end{tabular}

Phần lớn bệnh nhân phình động mạch chủ bụng là nam (chiếm 83,3\%). Bệnh nhân > 60 tuổi (chiếm $75 \%$ ), chỉ có $2,8 \%$ ở lứa tuổi $\leq 50$. Tuổi trung bình ở nhóm nghiên cứu 72,0 010,2 tuổi (nhỏ nhất 47 tuổi, lớn nhất 94 tuổi).

\subsubsection{Các yếu tố nguy co}


Không rõ yếu tố nguy cơ

Tăng huyết áp

Đái tháo đường

Hút thuốc

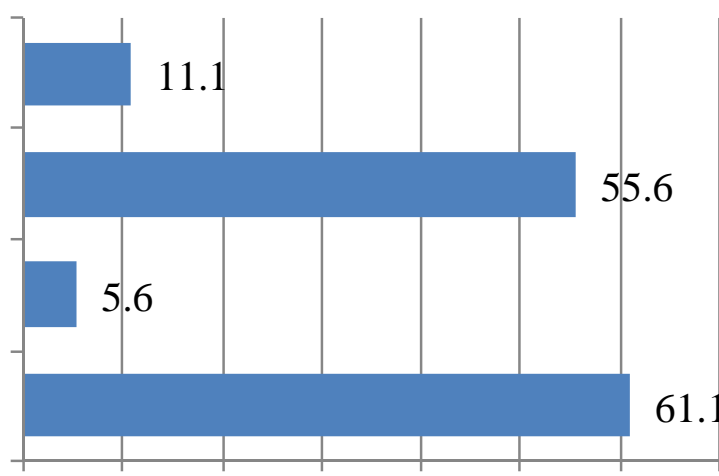

$\begin{array}{llllllll}0 & 10 & 20 & 30 & 40 & 50 & 60 & 70\end{array}$

Tỉ lệ \%

\subsubsection{Lý do vào viện}

Biểu đồ 3.1. Tỷ lệ các yếu tố nguy co

Bảng 3.2. Các lý do vào viện

\begin{tabular}{|l|c|c|}
\hline Triệu chứng & n & \% \\
\hline Đau bụng & 25 & 69,4 \\
\hline Khối u đập trong ổ bụng & 5 & 13,9 \\
\hline Không có triệu chứng & 6 & 16,7 \\
\hline
\end{tabular}

3.2. Các đặc điểm khối phình ĐMC bụng trên siêu âm và CLVT 64 dãy:

3.2.1. Kích thước của khối phình động mạch chủ bụng (PÐMCB)

Bảng 3.3. Kích thước của khối phình

\begin{tabular}{|c|c|c|c|c|c|c|}
\hline \multirow{2}{*}{\multicolumn{2}{|c|}{ Kích thước của khối PĐMCB }} & \multicolumn{2}{|c|}{ Siêu âm } & \multicolumn{2}{|c|}{ CLVT } & \multirow{2}{*}{ Kappa } \\
\hline & & $\mathbf{N}$ & $\%$ & $\mathbf{N}$ & $\%$ & \\
\hline \multirow{6}{*}{ Đường kính ngang } & $3,1-4 \mathrm{~cm}$ & 9 & 25,0 & 7 & 19,4 & \multirow{6}{*}{$\begin{array}{c}0,773 \\
P<0,001\end{array}$} \\
\hline & $4,1-5 \mathrm{~cm}$ & 9 & 25,0 & 13 & 36,1 & \\
\hline & $5,1-6 \mathrm{~cm}$ & 8 & 22,2 & 5 & 13,9 & \\
\hline & $6,1-7 \mathrm{~cm}$ & 4 & 11,1 & 5 & 13,9 & \\
\hline & $7,1-8 \mathrm{~cm}$ & 6 & 16,7 & 4 & 11,1 & \\
\hline & $>8 \mathrm{~cm}$ & 0 & 0 & 2 & 5,6 & \\
\hline \multirow{6}{*}{ Đường kính trước sau } & $3,1-4 \mathrm{~cm}$ & 12 & 33,3 & 10 & 27,8 & \multirow{6}{*}{$\begin{array}{c}\mathbf{0 , 8 1 9} \\
\mathbf{P}<\mathbf{0 , 0 0 1}\end{array}$} \\
\hline & $4,1-5 \mathrm{~cm}$ & 7 & 19,4 & 11 & 30,6 & \\
\hline & $5,1-6 \mathrm{~cm}$ & 8 & 22,2 & 7 & 19,4 & \\
\hline & $6,1-7 \mathrm{~cm}$ & 2 & 5,6 & 1 & 2,8 & \\
\hline & $7,1-8 \mathrm{~cm}$ & 7 & 19,4 & 7 & 19,4 & \\
\hline & $>8 \mathrm{~cm}$ & 0 & 0 & 0 & 0 & \\
\hline
\end{tabular}




\begin{tabular}{|c|c|c|c|c|c|c|}
\hline \multirow{6}{*}{ Chiều dài khối phình } & $4,1-6 \mathrm{~cm}$ & 7 & 19,4 & 4 & 11,1 & \multirow{6}{*}{$\begin{array}{c}\mathbf{0 , 7 7 7} \\
\mathbf{P}<\mathbf{0 , 0 0 1}\end{array}$} \\
\hline & $6,1-8 \mathrm{~cm}$ & 14 & 38,9 & 14 & 38,9 & \\
\hline & $8,1-10 \mathrm{~cm}$ & 8 & 22,2 & 7 & 19,4 & \\
\hline & $10,1-12 \mathrm{~cm}$ & 3 & 8,3 & 7 & 19,4 & \\
\hline & $12,1-14 \mathrm{~cm}$ & 2 & 5,6 & 0 & 0 & \\
\hline & $>14 \mathrm{~cm}$ & 2 & 5,6 & 4 & 11,1 & \\
\hline \multirow{4}{*}{ Đường kính cổ trên } & $1,1-2 \mathrm{~cm}$ & 6 & 16,7 & 9 & 25 & \multirow{4}{*}{$\begin{array}{c}\mathbf{0 , 7 4 9} \\
\mathbf{P}<\mathbf{0 , 0 0 1}\end{array}$} \\
\hline & $2,1-3 \mathrm{~cm}$ & 25 & 69,4 & 20 & 55,6 & \\
\hline & $3,1-4 \mathrm{~cm}$ & 4 & 11,1 & 6 & 16,7 & \\
\hline & $4,1-5 \mathrm{~cm}$ & 1 & 2,8 & 1 & 2,8 & \\
\hline
\end{tabular}

Có $\geq 50 \%$ trường hợp đường kính ngang và đường kính trước sau khối phình $\leq 5 \mathrm{~cm}$. Khối phình có chiều dài $6-10 \mathrm{~cm}$ chiếm tỉ lệ cao nhất, đa số khối phình có đường kính cổ trên từ $2-3 \mathrm{~cm}$. Có mức độ phù hợp chặt chẽ về kích thước khối phình giữa siêu âm và cắt lớp vi tính với Kappa $>0,7(\mathrm{P}<0,001)$.

\subsubsection{Hình dạng và giới hạn của khối phình động mạch chủ bụng}

Bảng 3.4. Hình dạng và giới hạn của khối phình

\begin{tabular}{|c|c|c|c|c|c|c|}
\hline \multirow{2}{*}{\multicolumn{2}{|c|}{ Hình dạng và giới hạn của khối phình }} & \multicolumn{2}{|c|}{ Siêu âm } & \multicolumn{2}{|c|}{ CLVT } & \multirow{2}{*}{ Kappa } \\
\hline & & $\mathbf{N}$ & $\%$ & $\mathbf{N}$ & $\%$ & \\
\hline \multirow{2}{*}{$\begin{array}{c}\text { Hình dạng của } \\
\text { khối phình }\end{array}$} & Hình thoi & 33 & 91,7 & 33 & 91,7 & \multirow[t]{2}{*}{1} \\
\hline & Hình túi & 3 & 8,3 & 3 & 8,3 & \\
\hline \multirow{2}{*}{$\begin{array}{c}\text { Giới hạn trên của } \\
\text { khối phình }\end{array}$} & Trên ĐM thận & 4 & 11,2 & 3 & 8,3 & \multirow{2}{*}{$\begin{array}{c}0,842 \\
p<0,001\end{array}$} \\
\hline & Dưới ĐM thận & 32 & 88,8 & 33 & 91,7 & \\
\hline \multirow{2}{*}{$\begin{array}{c}\text { Giới hạn dưới của } \\
\text { khối phình }\end{array}$} & Trên ĐM chậu & 6 & 17,7 & 5 & 13,9 & \multirow{2}{*}{$\begin{array}{c}0,893 \\
\mathrm{p}<\mathbf{0 , 0 0 1}\end{array}$} \\
\hline & Lan tới ĐM chậu & 30 & 83,3 & 31 & 86,1 & \\
\hline
\end{tabular}

Khối phình có dạng hình thoi chiếm tỉ lệ 91,7\%. Phần lớn trường hợp khối phình ở dưới động mạch thận, và lan tới động mạch chậu $>80 \%$. Có sự phù hợp hầu như hoàn toàn giữa siêu âm và CLVT với Kappa $>0,8(\mathrm{P}<0,001)$. 


\subsection{3. Đặc điểm của huyết khối và tình trạng xơ vũa trong khối PĐMCB}

Bảng 3.5. Đặc điểm huyết khối và tình trạng xơ vũa trong khối phình

\begin{tabular}{|c|c|c|c|c|c|c|}
\hline \multirow{2}{*}{\multicolumn{2}{|c|}{$\begin{array}{c}\text { Huyết khối và tình trạng xơ vữa trong } \\
\text { khối PĐMCB }\end{array}$}} & \multicolumn{2}{|c|}{ Siêu âm } & \multicolumn{2}{|c|}{ CLVT } & \multirow[t]{2}{*}{ Kappa } \\
\hline & & \multirow{2}{*}{$\begin{array}{l}\mathbf{N} \\
32\end{array}$} & \multirow{2}{*}{$\begin{array}{c}\% \\
88,8\end{array}$} & \multirow{2}{*}{$\begin{array}{l}\mathbf{N} \\
33\end{array}$} & \multirow{2}{*}{$\begin{array}{c}\% \\
91,7\end{array}$} & \\
\hline Huyết khối trong khối & Có & & & & & 0,842 \\
\hline phình & Không & 4 & 11,2 & 3 & 8,3 & $\mathrm{p}<0,001$ \\
\hline \multirow[t]{2}{*}{ Tính chất huyết khối } & Không đồng nhất & 4 & 12,5 & 5 & 12,5 & \multirow[t]{2}{*}{1} \\
\hline & Đồng nhất & 28 & 87,5 & 28 & 87,5 & \\
\hline \multirow{2}{*}{$\begin{array}{l}\text { Viêm quanh khối } \\
\text { phình }\end{array}$} & Có & 3 & 8,3 & 4 & 11,1 & \multirow{2}{*}{$\begin{array}{c}0,842 \\
p<0,001\end{array}$} \\
\hline & Không & 33 & 91,7 & 32 & 88,9 & \\
\hline \multirow[t]{2}{*}{ Bóc tách nội mạc } & Có & 2 & 5,6 & 2 & 5,6 & \multirow[t]{2}{*}{1} \\
\hline & Không & 34 & 94,4 & 34 & 94,4 & \\
\hline \multirow[t]{2}{*}{ Xo' vữa, vôi hóa } & Có & 27 & 75,0 & 29 & 80,6 & \multirow{2}{*}{$\begin{array}{c}0,84 \\
\mathbf{p}<0,001\end{array}$} \\
\hline & Không & 9 & 25,0 & 7 & 19,4 & \\
\hline
\end{tabular}

Khối phình có huyết khối đồng nhất bám thành, không kèm viêm quanh khối phình và không có bóc tách nội mạc chiếm tỉ lệ cao $>85 \%$. Tuy nhiên đa số khối phình bị xơ vữa thành chiếm tỉ lệ $\geq$ $75 \%$. Có sự phù hợp hầu như hoàn toàn giữa siêu âm và hình ảnh cắt lớp vi tính với chỉ số kappa > $0,8(\mathrm{P}<0,001)$.

\section{BÀN LUẬN}

\subsection{Các đặc điểm lâm sàng và cận lâm sàng} của đối tượng nghiên cứu:

Phình ĐMC bụng đa số gặp ở nam hơn là nữ, nam/nữ: 4/1 [1]. Kết quả nghiên cứu của chúng tôi cũng tương tự, khi nam giới chiếm $83,3 \%$, gấp gần 5 lần nữ giới. Điều này được giải thích có thể liên quan đến nam giới có thói quen sinh hoạt hay hút thuốc, uống bia rượu nhiều hơn nữ giới. PĐMCB hay gặp ở người có tuổi (> 60 tuổi) và tỷ lệ bệnh tăng dần theo tuổi, có thể được giải thích do càng cao tuổi thì thành mạch dễ bị xơ vữa nên giảm tính đàn hồi của thành mạch dẫn đến dễ bị phình mạch hơn. Qua nghiên cứu chúng tôi thấy PĐMCB có liên quan đến hút thuốc lá, chúng tôi có 22/36 chiếm tỷ lệ $61,1 \%$ bệnh nhân có hút thuốc lá ở những bệnh nhân này thường hút thuốc lá số lượng nhiều và kéo dài trong nhiều năm (>20 gói năm). Kết quả này cũng được ghi nhận ở nhiều tác giả khác, ở Pháp, tỷ lệ mắc PĐMCB ở người hút thuốc lá cao gấp từ 5 đến 10 lần so với người không hút thuốc lá, nguyên nhân được giải thích là do các thành phần có trong thuốc lá kích thích các men protease hoạt động tấn công và làm phá hủy lớp collagen ở thành mạch [14], [12]. Theo nghiên cứu của chúng tôi và nhiều tác giả thấy bệnh $\mathrm{PĐMCB}$ có liên quan nhiều đến bệnh tăng huyết áp. Huyết áp càng cao và kéo dài thì tỷ lệ $\mathrm{PĐMCB}$ càng nhiều và nguy có vỡ càng cao. Trong nghiên cứu của chúng tôi có 20/36 chiếm tỷ lệ 55,6\% bệnh nhân có tăng huyết áp. Tỷ lệ này cũng tương đương các tác giả trong nước như: Cao Văn Thịnh là 62\%, Văn Tần là 60\%, Phạm Hồng Đức là 64,28\% [1]. Đối với liên quan đến bệnh đái tháo đường theo nghiên cứu của chúng tôi trên 36 bệnh nhân $\mathrm{PĐMCB} \mathrm{chỉ}$ có 2 bệnh nhân bị đái tháo đường chiếm tỷ lệ 5,6\%; theo Đoàn Văn Hoan là 1,9\% [2], theo Hoàng Việt Dũng và Đoàn Quốc Hung là 9,4\%. Theo nghiên cứu của các tác giả nước ngoài tỷ lệ bệnh nhân bị PĐMCB có bị đái tháo đường chiếm tỷ lệ cao hơn, 
theo Dr Yves Castier chiếm tỷ lệ 11\% [13], [14]. Triệu chứng hay gặp khi bệnh nhân vào viện là đau bụng, bệnh nhân tự sờ thấy khối u đập trong ổ bụng. PĐMCB có thể không có triệu chứng được phát hiện tình cờ do đi khám các bệnh khác hoặc đi khám siêu âm kiểm tra.

\subsection{Các đặc điểm khối phình ĐMC bụng trên siêu âm và CLVT 64 dãy:}

Kích thước của khối phình tăng dần theo thời gian do đó cần phải theo dõi định kỳ để chỉ định mổ kịp thời tránh biến chứng vỡ túi phình. Theo Darling tỷ lệ vỡ của khối phình tăng đều đặn cùng với sự tăng kích thước của khối phình, đường kính ngang lớn nhất dưới $5 \mathrm{~cm}$ thì tỷ lệ vỡ là $18 \%$, đường kính từ $5-7 \mathrm{~cm}$ là $20 \%$, đường kính $7-10 \mathrm{~cm}$ là $59 \%$ và vỡ chiếm đến $95 \%$ ở khối phình $>10 \mathrm{~cm}$. Theo nghiên cứu của các bác sĩ Đại học Michigan Hoa Kỳ (2006), thì tỷ lệ vỡ trong 1 năm của khối phình có kích thước 5,5-6cm là 9\%; khối phình 6$6,9 \mathrm{~cm}$ là $10 \%$, khối phình $>7 \mathrm{~cm}$ là $33 \%$ và đề nghị những khối phình $<5,5 \mathrm{~cm}$ nên được theo dõi bằng siêu âm định kỳ. Như vậy, siêu âm là phương tiện thăm khám không xâm lấn, dễ thực hiện, độ tin cậy cao (95\%), rẻ tiền cho phép thấy được hình ảnh trực tiếp của ĐMC bụng và các nhánh lên, kích thước của khối phình góp phần vào việc chẩn đoán xác định khối phình và còn có vai trò quan trọng trong việc theo dõi định kỳ PĐMCB kích thước nhỏ (chưa có chỉ định mổ) để quyết định can thiệp ngoại khoa kịp thời tránh biến chứng vỡ túi phình gây tử vong cho người bệnh. Ngoài ra siêu âm còn là phương tiện khảo sát giúp cho phẫu thuật viên lựa chọn prothèse trong việc phẫu thuật PĐMCB. Trên CLVT 64 dãy đầu dò việc đo các kích thước được thực hiện một cách nhanh chóng, dễ dàng và chính xác vì trên CLVT khối phình được thấy rõ trên nhiều mặt cắt và các trục, giới hạn của khối phình với xung quanh cũng rõ ràng. Kết quả nghiên cứu của chúng tôi phù hợp với các tác giả khác sử dụng CLVT để khảo sát kích thước khối phình.
Trong nghiên cứu của chúng tôi thì khối phình hình thoi chiếm tỷ lệ cao, điều này phù hợp với nghiên cứu của một số tác giả trong và ngoài nước. Khối phình hình túi hay còn gọi là giả phình. Trong nghiên cứu này, $\mathrm{PĐMCB} \mathrm{nằm}$ dưới ĐM thận chiếm tỷ lệ cao. Theo Cao Văn Thịnh tại bệnh viện Bình Dân, trong 95 ca PĐMCB có 71 ca phình dưới ĐM thận chiếm tỷ lệ $74,8 \%$, theo Đoàn Văn Hoan khi nghiên cứu 104 ca PĐMCB thì có 103 ca phình dưới ĐM thận chiếm tỷ lệ 99,1\% [2], theo Phạm Hồng Đức thì $\mathrm{PĐMCB} \mathrm{dưới} \mathrm{ĐM} \mathrm{thận} \mathrm{chiếm} \mathrm{tỷ} \mathrm{lệ}$ 95,8\%, Theo Lorraine và cộng sự khối phình dưới ĐM thận chiếm tỷ lệ $90 \%$. Nguyên nhân PĐMCB hay khu trú ở đoạn dưới thận là do các yếu tố giải phẫu và huyết động. Chất elastine trong lớp áo giữa ít hơn 2 lần so với đoạn ĐMC ngực, do đó tính chun giãn kém hơn. Thành mạch được nuôi dưỡng chủ yếu bởi sự thẩm thấu, mảng xơ vữa (chủ yếu ở thành sau) sẽ cản trở sự thẩm thấu này. Như vậy, trong bệnh lý PĐMCB thì chủ yếu là phình dưới ĐM thận, đây là đoạn phẫu thuật có hiệu quả nhất, có kết quả cao, ít tai biến cho bệnh nhân. Kết quả nghiên cứu của chúng tôi cũng phù hợp với một số tác giả, theo Đoàn Văn Hoan tỷ lệ khối phình lan xuống đến ĐM chậu là 88,5\% [2], theo Phạm Hồng Đức tỷ lệ khối phình lan xuống đến ĐM chậu là $70,83 \%$. SA là kỹ thuật giúp xác định giới hạn của khối phình so với ĐM chậu dễ dàng, nhưng trong một số trường hợp khi khối phình lan đến sát ĐM chậu việc xác định khối phình có lan vào ĐM chậu 2 bên hay không gặp khó khăn dù khảo sát bằng $\mathrm{SA}$ doppler. Trong khi đó CLVT với các lớp cắt mỏng và tái tạo nhiều mặt phẳng việc xác định mức độ lan của khối phình đến ĐM chậu dễ dàng hơn. Ngoài ra CLVT còn phát hiện ĐM chậu có phình hay thuyên tắc kèm theo hay không giúp cho việc tiên lượng bệnh. 
Trong nghiên cứu của chúng tôi có 2 trường hợp vỡ mạn tính khối phình có huyết khối bám thành không đồng nhất. PĐMCB gây rối loạn lưu thông dòng chảy trong lòng mạch nên dễ hình thành huyết khối bám ở thành ĐM. Việc xác định mức độ của huyết khối trong khối PĐMCB có vai trò quan trọng trong việc tiên lượng bệnh. $\mathrm{SA}$ và CLVT còn xác định được mức độ đồng nhất hay không đồng nhất của huyết khối trong khối phình, điều này rất quan trọng vì những khối phình có huyết khối không đồng nhất có tỷ lệ thấp nhưng rất nguy hiểm do sự tiêu vỡ của huyết khối, làm thành khối phình suy yếu và có thể dẫn tới vỡ khối phình. Do đó dấu hiệu huyết khối không đồng nhất là một dấu hiệu quan trọng trong việc tiên lượng của bệnh $\mathrm{PĐMCB} \mathrm{nên} \mathrm{khi} \mathrm{khảo} \mathrm{sát}$ khối phình bằng $\mathrm{SA}$ và $\mathrm{CLVT}$ chúng ta phải khảo sát kỹ mức độ của huyết khối trong khối phình. Bóc tách nội mạc động mạch cũng hay gặp trong $\mathrm{PĐMCB}$, sẽ hình thành hai lòng ĐM: Lòng thật và lòng giả. Có nhiều nguyên nhân gây $\mathrm{PĐMCB}$ nhưng chủ yếu là do xơ vữa thành ĐM chiếm tỷ lệ $91,1 \%$ các nguyên nhân gây ra PĐMCB. Theo nghiên cứu của Trần Thiện Hòa, Văn Tần và các cộng sự thì người có bệnh lý xơ vữa $Đ M$ có nguy cơ bị PĐMCB gấp 6 lần những người bình thường [1]. Theo Adam Z. Barkin và các công sụ thuộc hiệp hội y khoa Bắc Mỹ thì tỷ lệ khối PĐMCB có xơ vữa vôi hóa là 78,5\%. Như vậy, qua nghiên cứu của chúng tôi, đối chiếu với các tác giả trong và ngoài nước thấy $\mathrm{PĐMCB}$ chủ yếu là do xơ vữa $Đ M$. SA có thể dễ dàng xác định được các mảng xơ vữa có kích thước lớn hơn $2 \mathrm{~mm}$, CLVT là kỹ thuật phát hiện xơ vữa thành mạch và mức độ xơ vữa chính xác hơn $\mathrm{SA}$. Theo nghiên cứu của Đoàn Văn Hoan thì CLVT có độ chính xác là 92,3\% (SA là 85,6\%) [2]. Trong nghiên cứu của chúng tôi thì CLVT phát hiện được mảng xơ vữa nhiều hơn $\mathrm{SA}$ doppler 2 trường hợp.

\section{KẾT LUẬN}

Qua kết quả nghiên cứu về đặc điểm hình ảnh $\mathrm{PĐMCB}$ trên 36 bệnh nhân bằng kỹ thuật Siêu âm và CLVT 64 dãy đầu dò, chúng tôi rút ra kết luận sau:

5.1. Phình ĐMC bụng hay gặp ở nam giới $(83,3 \%)$, độ tuổi hay gặp nhất là > 60 tuổi. Yếu tố nguy cơ chủ yếu là hút thuốc lá và tăng huyết áp. Đa số bệnh nhân vào viện với triệu chứng đau bụng $(69,4 \%)$.

Về kích thước của khối phình, đa số khối phình có đường kính ngang $\leq 5 \mathrm{~cm}(50 \%$ trên siêu âm và $55,5 \%$ trên CLVT). Đường kính trước sau của khối phình phần lớn $\leq 5 \mathrm{~cm}(52,7 \%$ trên siêu âm và $58,4 \%$ trên CLVT). Chiều dài của khối phình từ $6-10 \mathrm{~cm}$ chiếm tỉ lệ cao nhất $(61,1 \%$ trên siêu âm và $58,3 \%$ trên CLVT).

Đa số khối PĐMCB có hình thoi chiếm $91,7 \%$ trên cả siêu âm và CLVT. Vị trí thường nằm dưới chổ xuất phát của $\mathrm{ĐM}$ thận $(88,8 \%$ trên siêu âm và $91,7 \%$ trên CLVT). Và đa phần khối phình lan tới ĐM chậu (83,3\% trên siêu âm và $86,1 \%$ trên CLVT).

Phình ĐMC bụng thường kèm theo xơ vữa vôi hóa thành mạch $(75 \%$ trên siêu âm và $80,6 \%$ trên CLVT), đồng thời $5,6 \%$ trường hợp có kèm theo bóc tách nội mạc. Tình trạng huyết khối bám thành chiếm tỉ lệ cao $(88,8 \%$ trên siêu âm và 91,7\% trên CLVT).

5.2. Siêu âm và CLVT 64 dãy đầu dò là hai kỹ thuật chẩn đoán hình ảnh rất quan trọng trong việc chẩn đoán, điều trị và theo dõi bệnh nhân PĐMCB. Có sự phù hợp chặt chẽ giữa các thông số thu được trên siêu âm và CLVT trong bệnh lý $\mathrm{PĐMCB} \mathrm{với}$ kappa $>0,7(\mathrm{P}<0,001)$.

Tóm lại, PĐMCB là bệnh thường gặp ở Việt Nam, bệnh có thể gây ra nhiều biến chứng nguy hiểm đối với bệnh nhân. Việc phối hợp giữa 
siêu âm và CLVT 64 dãy đầu dò có vai trò quan trọng trong việc tầm soát, chẩn đoán và chuẩn bị toàn diện trước phẫu thuật cũng như theo dõi sau phẫu thuật ở bệnh nhân PĐMCB.

\section{TÀI LIỆU THAM KHẢO}

1. Trần Thiện Hòa, Văn Tần, Hà Chí Độ, Bùi Thị Hương Giang (2006), "Phình động mạch chủ bụng dưới thận: Tần suất và các yếu tố nguy cơ qua khảo sát 4807 người trên 50 tuổi tại 24 quận huyện thành phố Hồ Chí Minh", Chuyên đề: Phẫu thuật tim mạch và lồng ngực Việt Nam, tr. 180-191.

2. Đoàn Văn Hoan (2009), "Nghiên cứu đặc điểm hình ảnh và giá trị của chụp cắt lớp vi tính xoắn ốc trong chẩn đoán phình động mạch chủ bụng dưới thận”, Luận án Tiến sĩ Y học.

3. Nguyễn Thiện Hùng, Phan Thanh Hải và cs (1998), "Siêu âm chẩn đoán phình động mạch chủ bụng và dự hậu sau 10 năm", Y học thực hành, hội Y dược học Tp Hồ Chí Minh, (3), tr. 3-7.

4. Nguyễn Văn Mão (2006), "Phồng động mạch chủ bụng”, Bài giảng bệnh học ngoại khoa, tr. 156- 160.

5. Nguyễn Duy Tân, Nguyễn Văn Khôi, Trần Quyết Tiến, Đồng Lưu Ba, Nguyễn Đức Khuê, Hà Thanh Bình (2008), "Chẩn đoán và xử trí phình động mạch chủ bụng dưới thận tại khoa ngoại lồng ngực bệnh viện Chợ Rẫy", Chuyên đề phẫu thuật tim mạch và lồng ngực Việt Nam, tr. 336-340.

6. Lê Ngọc Thành, Đỗ Hoàng Tuấn (1999), "Phồng động mạch chủ bụng vỡ: Nhân 10 trường hợp được mổ tại Bệnh viện Việt Đức", Ngoại khoa(3), tr. 19-23.

7. Abbas A, Smith A, Cecelja M, Waltham M. (2012), Assessment of the accuracy of AortaScan for detection of abdominal aortic aneurysm (AAA), Eur J Vasc Endovasc Surg, 43(2), pp:167-70.
8. Long A, Bui HT, Barbe C, Henni AH, Journet J, Metz D, Nazeyrollas P (2010), Prevalence of abdominal aortic aneurysm and large infrarenal aorta in patients with acute coronary syndrome and proven coronary stenosis: a prospective monocenter study, Ann Vasc Surg, 24(5), pp:602-8.

9. Van Walraven C, Wong J, Morant K, Jennings A, Jetty P, Forster AJ (2010), Incidence, follow-up, and outcomes of incidental abdominal aortic aneurysms, J Vasc Surg, 52(2), pp:282-9.

10. Walter A Tan, MD, (2011), Abdominal Aortic Aneurysm Rupture Imaging.

11. Wells C. E., Pugh N. D. and Woodcock j J. P. (2011), Abdominal aortic aneurysm detection by common femoral artery Doppler ultrasound waveform analysis, Journal of Medical Engineering \& Technology, 35(1), pp:34-39.

12. Alexandre Ponti, Nicolas Murith (2012), "Anevrismes de l'aorte abdominale: connaissances actuelles et traitment endovasculaire", Rev Med Suisse, 8:1564-1568.

13. Boccalon H, J.P. Bosssavy (2000), "Anevrismes de l'aorte abdominale et de ses branches", Service de chirugie cardio-vasculaire.

14. Pr. Van Tan, Ho Khanh Duc (2005), "Hypertension arterielle, facteur de risque pour les Anevrismes de l'aorte abdominale sous renale", Troisiemes rencontres internationales Franco Vietnamiennes de pathologie cardio - vasculaire medico - chirurgicale, pp:147-148.

15. Yves Castier (2011), "Anevrismes de l'aorte abdominale sous-renale", Sang thromose Vaisseaux, 23(7):348-359. 